\title{
Analysis of Media Influence in Structuring a Political Position
}

\author{
$1^{\text {st }}$ Jean Nsengiyumva* \\ Master of Communication Science \\ Universitas Atma Jaya Yogyakarta \\ Yogyakarta, Indonesia \\ nsengjean1@gmail.com
}

\author{
$2^{\text {nd }}$ Lukas S Ispandriarno \\ Master of Communication Science \\ Universitas Atma Jaya Yogyakarta \\ Yogyakarta, Indonesia \\ lukas.ispandriarno@yahoo.com
}

\begin{abstract}
This study is based on the analysis of results from 28 qualitative and 10 quantitative types of research which evocated issues related to the impact of media in the political field. This study tends to analyze the contribution of media in a political position. However, whatever the media content is (positive or negative), it will be considered its contribution to structuring and determining the position of politics by changing negatively or positively the attitudes of the politicians among whom there are leaders of some states. Therefore, the politicians' behavior and media content with its impact on society will be considered in analyzing the way media can contribute to the determination of political position in any society. The outcome of this qualitative study confirmed that positively or negatively, media play a major role in changing the politicians' attitudes.
\end{abstract}

Keywords-media content, political position, people behaviors, politicians' attitude, society

\section{INTRODUCTION}

Nowadays, the current opinion in behavioral sciences argues that individual personality, emotion, and political ideology cause some attitudes among different politicians all over the world. This leads to a certain position of politics wherever it is practiced. Apart from that, media has been revealed as another factor influencing the behavior of people in political practice in any given society. Recently, the relations between the media and politics have expanded. Due to the spread of media and the use of its content by different people, they still wonder if the media can influence political behavior to determine the political position. Further, they ask themselves how media can influence in putting up the structure of political position [1]. Today, education is emphasizing the role of deep political dialogue in empowering democracy with its principles since both interpersonal communication and mediation are the most important in promoting citizen involvement, but also intensifying dissemination [2].

Therefore, the present study investigates the theories talking about the concerned issue and beyond, it uses some related techniques to know the point of view of other studies of the same. preparing electronic versions of their papers. All standard paper components have been specified for three reasons: (1) ease of use when formatting individual papers, (2) automatic compliance to electronic requirements that facilitate the concurrent or later production of electronic products, and (3) conformity of style throughout conference proceedings. Margins, column widths, line spacing, and type styles are built-in; examples of the type styles are provided throughout this document and are identified in italic type, within parentheses, following the example. Some components, such as multi-leveled equations, graphics, and tables are not prescribed, although the various table text styles are provided.

\section{THEORETICAL FRAMEWORK}

Determination of the impact of behavior involves control of the use of media as contributions of opinions, beliefs, values, and behavior. Various studies on the impact of media on society say that media content has somehow influenced the public which is also its audience. Research from the middle of the 20th century has an objective view on the influence of the content of the media in providing the structure of politics by highlighting the attitudes characterizing the politicians in a given society. The theory that we understand the role of the media in shaping politics behavior user and view that content.

There is a lot of literature related to how media influence people in different perspectives according to every researchers' interests. Hence, the agenda-setting theory states that the public presentation of the information that you receive determines the highly considerable and important media [3]. In other words, the topics introduced in different kinds of media will make a difference among media due to the way those topics and contents attract the public. Highlighting the relationship between media and politics, by also highlighting the role of news' topics in attracting people, it can be seen that politicians seem to be the first people to be interested in the news whose topics are political. they become interested in political topics due to the fact the always feel curious in recognizing what media content tells the public about them.

Furthermore, almost 50 years, the studies on the public agenda theory prove that what people think powerful result from the media's released issues to which media pay attention like the media attention, and this relationship remains in the new environment of the media, the choice of the top [4]. Experiments have shown that even understanding of the satire in the media can raise knowledge, and protruding from claims of some problems. However, the attitude of users affects not only the volume or significance of media coverage but also the level of coverage that they perceive [5].

The second theory regarding this topic is the magic bullet or hypodermic needle theory of communication effects which proved that media were extremely powerful in shaping 
public opinion where media messages influence individuals heavily and directly[3]. Once information related political issue is broadcasted on Radio or any other type of media it stimulates the reaction of the audience immediately that reaction can support the politician's opinion and attitudes by criticizing them. In the same line with the present study, the media play a role in putting up the position of politics by transmitting a message critiquing some politicians' behavior and ideologies.

Further, apart from politicians who read the media themselves, the people also who read the concerned media criticize politicians the mentioned names in the content of media. As a result, as a politician, after reading what media talk about your behavior, you can change the negative attitudes or improve the positive ones. Further, based on their social needs, the audience's reaction to the pointed politician will push you on changing some of your bad behavior of enhancing those which are good. Hence, the change made after the distribution of the media content that broadcasted such as news will determine the position of politics in a given society.

Then, interpretive effects theories which include theories focus on looking at the reputation and structure of attitudes results from the media [3]. Based on the topic of this paper, this theory should be taken into account. human behavior changes caused by the news content are constantly connected to the theory above. In this case, whenever the media content has an impact on someone's attitude, that change determines the new status of a person in a society.

Therefore, a lot of media's content show their users 'emotions about some politicians' attitudes. Some of them seem to be interested while others are greatly shocked by the way they behave. Because of that, the concerned people (pointed politicians) may modify the way they behave based on the critiques appear in the content of media. Thus, this modification will be one element proving the position of politics in political contexts. As a result, it can be concluded that the existing position has been influenced by trending media content.

Look for content and views, the theories of the agendasetting, hypodermic-needle, interpretive effects determine how media influence the way people think about them and their content [3]. Due to emotional confusion between two parties; the media and politicians, the related literature review such as Cacciatore et al. [6] give suggestions of limitations of the study advised classification of "information handling the similar logic investigation, not "highlights some of the issues on the other side. Concerning theoretical tags, attributes, and media content should include informational issues that affect the news user's behavior.

In terms of research focusing on the user, not the contents, choosing assistant exposure claims that people are more likely to seek and destroy the policy of the media that is consistent and not on their political empty. This select rested to increase political polarization[7] assistant select exposure effect is that the media public only themselves join the room where they met disagree or agree with the statement. However, research that recognizes the high-choice of media environment offered by the Internet has found that those who are politically interested and those whose diets vary avoid echo chambers [8].
Web analytics data, rather than self-report measures which are typically used, shows that online news audiences first visit "famous brand news" to the site cover-up various audiences partisan ideology [9]. Although people tend to seek the political media that they approve of, the current environment allows for little exposure to counter-attitudes, especially for those who are very interested. Other researchers have found evidence that while the social media and personalized is associated with more ideological divisions Navigator directly with those associated with exposure to different perspectives [10].

According to the user-oriented theory, the hostile media phenomenon (HMP) illustrates the possibility of individuals who are deeply involved in viewing media coverage as a bias towards their position. Those who choose congruent political media feel prejudice among the "media" in general, but less so in the media of their choosing [11]. There is evidence that the HMP pushes some users out of attitude to action. Research shows that, for liberals, the perception of the media as an enemy is positively related to climate change activism [12].

Political communication research also examines the influence of media entertainment on a political position by using different theoretical approaches. For example, the identification of the main character in a TV program while it is involved in the storyline and gender mediate the relationship between beliefs and attitudes about the gender of the people, if they have a positive attitude more because the characteristics redness over the base became the address [13]. Likewise, Holding and Sherrill [14] analyzed three female TV: characters lead female secretary, Scandal, and Good Wife.

They found that the vessel Parasocial relationship with these characters, the feelings of the characters and their storylines, is associated with an increase in political interest, efficiency, and participation. This relationship occurs because the examples of women in leadership, which historically number is limited, can politically get a commitment from the audience, mostly women inspire. The relationship between politics and media entertainment with political interest and support in experimental work [15]. with a significant impact on the perception of social policy participation [16]

This relationship occurs because the examples of women in leadership, which historically number is limited, can politically get a commitment from the audience, mostly women inspire. the relationship between politics and media entertainment with political interest and support in experimental work [15]. with significant impact on the perception of social policy [16].

\section{METHODS AND RESULTS OF RESEARCH}

Nowadays, researchers are still focusing on the relationship between the media and the big political attitudes. This model is often used in studies of the effects of media content and information. For example, a pilot test of the impact of the media in political polarization indicates that as the media portrayed as a polarized electorate, participants responded with great reluctance opposing political parties [17].

An analytic approach to content may also be relevant, at least in understanding media content offered to media 
consumers. For example, using data from both content analysis and in-depth interviews,[18] found that media attention can help in political advocacy groups that achieve their goals, depending on how they work. this media coverage was covered. Also, examining the influence of certain media outlets has proven useful in the latest scholarships. In particular, consumption of Fox News content has been shown to influence policy preferences [19].

a new approach to the study of such proceeds to inform data mining and analysis of informal networks, in particular, the use of data from social media. These techniques include computational methods often try to find a connection between the use of the media and political impact. For example, in an analysis of more than 20 million tweets, [20] identified as "a series of activists" who work for some kind of joint action. Besides, using network analysis techniques recently increased and research results are still an important pillar in the main press con-premise behavior [21]

\subsection{Average and mediating variables}

The key to understanding the impact of the media on the outcome of the political attitudes of individuals was available. View of exposure to the media can be adjusted by the use of the media, where most of the research focuses on the development of negative attitudes [22]. But reinforcement attitudes, especially attitudes led ideology, it is equally important to be considered [23]. This consolidation involves the promotional character of a person's character rather than change their direction.

Experimental research shows that what people know about certain issues before exposure to the media and their socio-political orientation, and whether media messages are politicized, influences the subject's attitude [24] These effects vary depending on the amount of knowledge, the degree of partiality and the direction of the politicization of the media. Also, this attitude can influence individual responses to media content, as explained by the process of selective exposure and confirmation bias [25], where individuals tend to prefer coherent attitude information, but defense motives reinforce this preference.

Other factors, like the high level in trusting media contents[26], may regulate the relationship between media messages and related attitudes and behaviors in ways that facilitate democratic values; However, a combination of high knowledge and low self-esteem leads to the validity of the conspiracy theory [27]. Political intelligence can also influence political attitudes in a way that confuses individual evaluations of political actors, leading to the worst judgment of all politicians [28]. Also, Feldman et al. [12] confirmed that the moderate effects of hostile media events, in which HMP promotes action against climate change in the open air, but does not support it. Different identities, such as political parties, also tend to moderate the relationship between media use and political attitudes (for example, [14, 31].

Concerning the variable intervention, Wojcieszak et al. [29] experimentally tested the effects of media consumption on cognitive, affective, and attitudinal changes. Participants exposed to attitudinal arguments were more likely to engage in political activities, whereas exposure to antitrust arguments did not work, so compared to balanced news. The effects of counter-argumentative arguments are mediated through an understanding of the problem, anger, positive emotions, and the power of the relationship. McGregor and
Moura [30] also found the role of second-screen mediation, where TV news consumption acts as an independent variable and political participation as a dependent variable.

The use of a second screen while watching political television was linked to increased political participation. This process of second screening is also linked to an openness to changing one's political opinion, and these results are stronger among those who use social media more often [13]. Moreover, emotions can exacerbate the impact of online information on political attitudes and behavior. Recent studies have found that anger can participate, in particular, in the online political debate and lack of interest in stimulating different points of view, by pressing the echo chamber effect [33]. Holding and Parrott [24] also identified the relationship between anger and the search for political information and resources for online and offline exchange during elections.

To date, this product includes a discussion of the theory that our understanding of how the media affect political attitudes and methodological approaches that lead. Now back to the future potential for serious talks this line of research. Constantly changing landscape of media, researchers evaluate how the media work needs to influence political attitudes.

This change in the new environment-wing environment affect the availability, content, and an important element all can influence how the media affect political attitudes. In the first place, all the Internet offers selective exposure consonants to view messages and content from the perspective of accidental exposure. This shows that information through either found in one specific navigation information, search engine queries on a particular subject, exposure through social media, or write to the push notification may affect the news Apps effect.

Second, because the new environment affordances media content varies widely in terms of content and quality. For example, information hyper-partisan, at the intersection of media and alternatives assistant, and rely more on social media for distribution and rewarding challenges. In other words, the content of the traditional regular report must be manufactured for awakening preferences and feelings of click [31]. Future research should examine the effects of diet creates information hyper-partisan, especially on discriminatory feelings and spreading misinformation.

Finally, how people interact with media can influence their political position. Click, share, comment, and react to the information and add all the items of additional information that may affect users in. Indeed, Wegener comments designed - users can train a news article reads comments detected as hostile media source their position [32]. information in news stories and information structure is also influential in the comments section of the online conversation about political issues [33]. Furthermore, the fact that special populations such as women tend to participate in online discussions on policy issues certainly affects the content and scope of the online dialogue [34].

\section{CONCLUSION}

This study aimed to analyze the contribution of media in political position determination by deeply studying how negatively and positively media can play a major role in changing the politicians' attitudes. After analyzing different 
findings from the literature review, where a large number of researcher's opinions confirmed the positive impact of media for politicians' attitude and behavior change, the outcome of this study confirmed the influence of media contents in structuring political position.

Based on how media audience criticizes attitudes and behavior of politicians, this analysis shows that most of the time media become enemies of the politician but on the other side friends of people who need to share their opinion related political issues. The big challenge remains on how to handle the problem of those media which are hated by politicians especially for reporters or publishers of information related to the issue which can put down some respected politicians, are working in unsafe conditions in countries where there is no freedom of expression.

Many other realities related to political issues remain in the box of untold stories for those countries governed under dictatorship, because of the lack of media freedom. In that case, the media publication contents are controlled by the Government and there is no way to criticize politicians.

\section{REFERENCES}

P. Van Aelst et al., "Annals of the International Communication Association Political communication in a high-choice media environment: a challenge for democracy?," vol. 8985, no. May, pp. 2-27, 2017

D. V Shah, D. M. Mcleod, H. Rojas, and J. Cho, "Revising the Communication Mediation Model for a New Political," pp. 1-14, 2017.

[3] Vincent Mosco, The Political Economy of Communication, 2nd ed. 1 Oliver's Yard 55 City Road London EC1Y 1SP: SAGE Publications Ltd, 2009.

A. Shehata and J. Strömbäck, "Not ( Yet ) a New Era of Minimal Effects: A Study of Agenda Setting at the Aggregate and Individual Levels,” p. 22, 2013.

E. Stoycheff et al., "Agenda Cueing Effects of News and Social Media," Media Psychol., vol. 21, no. 2, pp. 182-201, 2018.

M. A. Cacciatore, D. A. Scheufele, S. Iyengar, and P. Relations, "The End of Framing As We Know it ... and the Future of Media Effects The End of Framing As We Know it ... and the Future of Media Effects," no. August 2015.

N. J. Stroud, "Polarization and Partisan Selective Exposure," vol. 60, pp. 556-576, 2010.

E. Dubois and G. Blank, "The echo chamber is overstated: the moderating effect of political interest and diverse media," vol. $4462,2018$.

J. L. Nelson and J. G. Webster, "The Myth of Partisan Selective Exposure: A Portrait of the Online Political News Audience," 2017.

[10] J. Rao, "FILTER BUBBLES , ECHO CHAMBERS , AND ONLINE NEWS CONSUMPTION,” pp. 24-29, 2016.

[11] M. Barnidge, H. G. De Zúñiga, and T. Diehl, "Second Screening and Political Persuasion on Social Media Second Screening and Political Persuasion on Social Media," J. Broadcast. Electron. Media, vol. 61, no. 2, pp. 309-331, 2017.

[12] L. Feldman, P. S. Hart, A. Leiserowitz, E. Maibach, and C. Roser-renouf, "Do Hostile Media Perceptions Lead to Action? The Role of Hostile Media Perceptions , Political Efficacy , and
Ideology in Predicting Climate Change Activism,” pp. 1-26, 2015

[13] T. K. Gillig, E. L. Rosenthal, S. T. Murphy, and K. L. Folb, "More than a Media Moment: The Influence of Televised Storylines on Viewers ' Attitudes toward Transgender People and Policies," 2017.

[14] J. Hoewe, L. A. Sherrill, J. Hoewe, and L. A. Sherrill, "The Influence of Female Lead Characters in Political TV Shows: Links to Political Engagement The Influence of Female Lead Characters in Political TV Shows: Links to Political Engagement," J. Broadcast. Electron. Media, vol. 63, no. 1, pp. 59-76, 2019.

[15] C. Weinmann, "Feeling Political Interest While Being Entertained? Explaining the Emotional Experience of Interest in Politics in the Context of Political Entertainment Programs," vol. 6, no. 2, pp. 123-141, 2017.

[16] N. Swigger, "The Effect of Gender Norms in Sitcoms on Support for Access to Abortion and Contraception," 2017.

[17] M. Levendusky and N. Malhotra, "Does Media Coverage of Partisan Polarization Affect Political Attitudes ?," no. September, 2015.

[18] I. De Bruycker, "Blessing or Curse for Advocacy? How News Media Attention Helps Advocacy Groups to Achieve Their Policy Goals Blessing or Curse for Advocacy? How News Media Attention Helps Advocacy Groups to Achieve Their Policy Goals," Polit. Commun., vol. 00, no. 00, pp. 1-24, 2018.

[19] G. Smith, "The Timing of Partisan Media Effects during a Presidential Election," 2016.

[20] M. T. Bastos and D. Mercea, "Serial activists : Political Twitter beyond influentials and the twittertariat," 2015.

[21] B. E. Weeks et al., "Partisan Enclaves or Shared Media Experiences? A Network Approach to Understanding Citizens, Political News Environments Partisan Enclaves or Shared Media Experiences? A Network Approach to Understanding Citizens ' Political News Environments," vol. 8151, no. May, 2016.

[22] J. Matthes and D. Schmuck, "The Effects of Anti-Immigrant Right-Wing Populist Ads on Implicit and Explicit Attitudes : A Moderated Mediation Model," pp. 1-26, 2015.

[23] P. S. N. Lee, C. Y. K. So, F. Lee, L. Leung, and M. Chan, "Telematics and Informatics Social media and political partisanship - A subaltern public sphere 's role in democracy," Telemat. Informatics, no. May, pp. 0-1, 2018.

[24] L. Ahern, C. Connolly-ahern, and J. Hoewe, "Worldviews, Issue Knowledge , and the Pollution of a Local Science Information Environment," 2016.

[25] S. Winter, M. J. Metzger, and A. J. Flanagin, "Selective Use of News Cues: A Multiple-Motive Perspective on Information Selection in Social Media Environments," vol. 66, pp. 669-693, 2016.

[26] A. Ardèvol-abreu and C. M. Hooker, "Online news creation , trust in the media, and political participation: Direct and moderating effects over time," 2017.

[27] K. L. Saunders, C. State, and C. E. Farhart, "Conspiracy Endorsement as Motivated Reasoning: The Moderating Roles of Political Knowledge and Trust,” vol. 00, no. 0, pp. 1-21, 2015.

[28] F. L. F. Lee, "The Spillover Effects of Political Scandals: The 
Moderating Role of Cynicism and Social Media Communications," 2017.

[29] M. Wojcieszak et al., "Partisan News and Political Participation : Exploring Mediated Relationships Partisan News and Political Participation : Exploring Mediated Relationships," vol. 4609, no. November, 2015.

[30] S. C. Mcgregor, R. R. Mourão, S. C. Mcgregor, and R. R. Mourão, "Second Screening Donald Trump : Conditional Indirect Effects on Political Participation Second Screening Donald Trump : Conditional Indirect Effects on Political Participation," J. Broadcast. Electron. Media, vol. 61, no. 2, pp. 264-290, 2017.

[31] M. Barnidge and C. Peacock, "A Third Wave of Selective Exposure Research? The Challenges Posed by Hyperpartisan News on Social Media,” vol. 7, no. 3, pp. 4-7, 2019.

[32] E. Lee, "That's Not the Way It Is : How User-Generated Media Bias," vol. 18, pp. 32-45, 2012.

[33] C. Peacock and N. J. Stroud, "The deliberative influence of comment section structure," 2017.

[34] E. Van Duyn, C. Peacock, and N. J. Stroud, "The Gender Gap in Online News Comment Sections,” pp. 1-16, 2019. 